\title{
The Image of the 2010 World Expo: Residents' Perspective
}

\author{
Kangjuan LV', Gyula Mosoni², Mengyi Wang ${ }^{3}$, Xiaosong Zheng ${ }^{4 *}$, Yan Sun ${ }^{5}$ \\ 1,3,4,5 SILC Business School, Shanghai University \\ 20 Chengzhong Road, JiaDing District, Shanghai, 201800, P.R.China \\ E-mail.lvkangjuan@shu.edu.cn,wmy.1009@163.com, littlepine88@163.com,nancysun@shu.edu.cn \\ ${ }^{2}$ School of Economics, Shanghai University \\ 99 Shangda Road, BaoShan District, Shanghai \\ E-mail.gyulamosoni@yahoo.com
}

cross $^{\text {ref }}$ http://dx.doi.org/10.5755/j01.ee.28.2.3048

\begin{abstract}
Hosting mega-events has been regarded as an effective catalyst for city branding. But increasing environmental cost of megaevents has been highlighted recently, which affected local residents' actual perception. The inconsistence between governments propagandizing benefits from holding mega-events and citizens' real experience will decrease the real effect of the events. This paper demonstrates the inconsistence by Shanghai example, which is a support to the theory of mega-event impact on city. Shanghai 2010 World Expo officially aimed to improve the quality of life and building a harmonious society, while there are fewer studies focusing on whether the proposed vision is accepted by citizens. This paper explored the influences with a particular focus on residents' attitudinal survey after the event from December 2010 to February 2011 and 148 respondents were collected. Using structural equation model, the results illustrated that surveyed residents recognized more with 4 dimensions (culture, environment, economic and technology), which reflected the harmony between man and nature, as well as harmony between spiritual and material content. However, they did not perceive the upgrade of community cohesion, communication between urban and rural areas, and living condition after the mega-event. In conclusion, the residents form their preconceptions based on both individual experience and official vision. The whole concept of Shanghai Expo is not totally recognized by local residents. This mismatch is related to the existence of social challenges and the absence of a two-way communication. Shanghai branding should properly conceptualize and manage the city's core values with residents' participation in policy making process.
\end{abstract}

Keywords: Mega-Event; Shanghai World Expo; Harmony Society; City Branding.

\section{Introduction}

As the deeper of globalization, the intensive urban competition for markets, resources, visitors and attention has been raised during the past two decades. Consequently, city branding has become a common marketing instrument adopted by governments to publicize a city's competitive advantages (Evans, 2003; Clark, 2006). Mega-events are frequently cited as catalysts to build a city's brand (Owen, 2005). Ritchie and Aitken (1984) early defined mega-events as a series of activities in order to achieve specific objectives, which are always one-time or recurring major events of limited duration, such as Olympics, World Expo and World Cup. However, it is uncertain whether the expected objectives can be realized considering examples where events may cause negative influences, including traffic jam, environmental pollution as well as cultural conflicts between residents and visitors (Tosun, 2002; Brain \& Mark, 2013).

Residents in the host city usually judge the event through their actual experience, stress on perceived personal benefits and expect developments could meet their needs (Zhang \& Zhao, 2009). Their perception may beyond the control of any official strategy (Kavaratzis \& Ashworth, 2006). The inconsistence between governments propagandizing benefits from mega-events and local citizens' actual perceptions on the events may affect dwellers' support and success of the events (Smidt-Jensen, 2006). What's worse, it is possible to trigger dissatisfaction, protests or even violent counterhegemonic behaviors among those marginal people such as the unemployed and the homeless (Pasotti, 2013; Antonella \& Cecilia, 2015). Therefore, better understanding of residents' perception and satisfaction level on the mega events can verify any mismatch, lessen discrepancy and receive communitywide support towards future event hosting.

The 2010 Shanghai World Expo was an endeavor of Shanghai Municipal government to brand the city with the theme "Better City, Better Life" (Zhang, 2013). The meaning of this theme was officially explained to improve the quality of life of local residents and build a harmonious, international and modern society (Shanghai Expo, 2008). "Harmonious society" included the improvements of social equity and justice, public services and moral standards (World Expo Shanghai 2010 Official Website, 2006). Many scholars have researched on the impacts of the 2010 World Expo focusing on respondents' perceptions and evaluations (Yu et al., 2012; Kim, et al., 2012; Wang et al., 2012; Xue et al., 2012). But there are fewer studies exploring whether the expected vision of the Shanghai government has been congruent with local citizens' actual perceptions. 
Therefore, the purpose of this study is twofold: (1) analyze the influences of the 2010 World Expo on Shanghai, with a particular focus on residents' satisfaction survey after the event, via structural equation modeling (SEM); (2) examine any significant differences between the government's vision and residents' perceptions of the event. The remainder of this study proceeds as follows. The next section gives a theoretical base and literature review about impacts of mega-events. The third part introduces the methods used in this paper. Results will be presented in the fourth section, followed by discussions in fifth part. Conclusion comes last.

\section{Literature Review}

\section{Theoretical Foundation}

Residents' perception is a prevalent scope to explore the impacts of mega-events. Residents are seen as key stakeholders by event organizers, whose supports are fundamental elements for operating successful and sustainable events (Getz, 2008; Baum et al., 2009).

Social exchange theory (SET) is one of the most widely used theoretical base for researching community and residents' perceptions of tourism impacts (Ap, 1992; Troy et al., 2011; Kim et al., 2015). This theory indicates that local residents are likely to change their perceptions of megaevents based on the expected value exchange (Ap, 1992). This exchange accompanies by an evaluation of the costs and benefits, if the residents are not satisfied, their negative perceptions will transfer into unsupportable behaviors for future events. On the other hand, if residents are satisfied, they will have positive perceptions and supportive behavioral intentions in the future (Andereck et al., 2005).

There are several factors influencing residents' evaluation about the costs and benefits of hosting a megaevent. Information provided by the national media and government agencies will shape locals' expectations. Besides, according to the social representations theory (SRT), locals form their own preconceptions based on individual's value and past experiences (Moscovici, 1982; Fredline \& Faulkner, 2002). Thus, extrinsic information and inherent preconceptions combined into initial perceptions on the event. This paper aims to reveal any difference between the perceived value by residents and the official value on the impact of mega-events, which gives evidence that social representative theory plays a role in mega-event.

\section{Perceived Impact of Mega-events}

Apart from economic impacts, recent research explores positive or negative perceived impacts from multi-dimension, such as social influences, cultural influences, environmental influences and political influences (Huang, 2012; Maximos et al., 2004; Hyun et al., 2006; John, 2002).

Expected economic impact is invariably a vital motivation for the host city. Several studies verify that a mega-event can affect tax revenues, employment and other economic revenues (Brain \& Mark, 2013). Most importantly, mega-events can spur the tourism industry by enlarging the tourist market and attracting visitors (Maximos et al., 2004). However, economic benefits are always exaggerated due to the likelihood of price inflation and increase in local taxes (Matheson, 2009). Therefore, net economic benefits and other non-economic effects should be paid more attention (Luo \& Lu, 2011).

The social influence of big events is mainly demonstrated by residents' perceived satisfaction about life quality, employment and community participation (Kiki et al., 2013; Arne \&Wolfgang, 2013; Lucio et al., 2011). Infrastructure and facilities, which can be used by citizens afterwards, are regarded as big benefits (Hyun et al., 2006). Besides, big events can create jobs, and workers from outskirts have more job chances to participate in the construction and maintenance of event-related infrastructure, offer security and food service (Brain \& Mark, 2013). But these new jobs are usually part-time or low-paying, which produce little value in the long term. It is also considered to cause social issues like traffic jam, noise, protest and crime, exclusions and forced evictions (Maximos et al., 2004).

Considering culture, mega-event can be a booster of the government to advocate value and promote reconciliation, citizens' cohesion, euphoria, self-esteem, patriotism and national pride (Fredline, 2005; Zhou \& Ap, 2009). Besides, it can improve cultural communication and understanding (Hyun et al., 2006). Hooper (2001) indicates mega-event participation provides a sense of well-being and social connection. Nevertheless, the clustering of diverse cultures may trigger conflicts between residents and visitors due to different standards of living and purchasing power gaps (Tosun, 2002).

'Green' environment has become a new theme of megaevents (Chernushenko \& Stubbs, 2005). In reality, from the positive side, mega-events can raise attention to protect physical landscape and local heritage. Moreover, they can redevelop the physical environment of the city by building new public facilities. From the negative side, mega-events may undermine natural resources, change land use, cause pollution and climate change (Andrea et al., 2009; Jones, 2008).

Mega event is an excellent platform to display and apply science and technology. In 2000, Sydney Olympic Village introduced solar energy systems, which represented new development in the building and construction industry (Andersen et al., 2004). In 2010 Shanghai Expo, many pavilions on display had adopted environmentally design and low-carbon technologies (Wang et al., 2011; Zhang, 2013). Meanwhile, these events reinforce people's awareness of environmental protection. The concept of "people oriented; people foremost" is also embodied in the events, such as the design of China Pavilion in Shanghai Expo (Wang et al., 2011).

Based on the literature above, this paper puts forward the hypotheses: the World Expo mega-event brings positive impact on economy, social factors, culture, environment, science and technology from residents' perspective as government expected. Social factors are demonstrated by life quality, community participation (Kiki et al., 2013; Arne \&Wolfgang, 2013; Lucio et al., 2011) and rural regions (Brain \& Mark, 2013). In the following section, the 2010 Shanghai World Expo is taken as example to verify these hypotheses.

\section{Methodology}

\section{Development of the Scale}

In this study, existing scales in literatures about tourism influences of large events were referred (Ap \& Crompton, 1998; Gursoy et al., 2002). A few studies have explored the 
evaluation of visitors or residents about the impacts of Shanghai World Expo. Yang and Wu (2012) surveyed Shanghai residents by 16 evaluation indexes, including cultural communication and city image. Qian and Zhu (2011) obtained visitors' perceived values of Shanghai Expo and constructed the evaluation index system from six aspects, including creativity, culture, technology, architecture, services, and infrastructure, with 28 segmented factors. Preuss's (2007) and Agha et al.'s (2012) listed the legacies of Olympic Games, which are also chosen as references.

Accordingly, this study designed 45 Likert-scaled specific items ( $1=$ strongly disagree to $5=$ strongly agree) for 7 dimensions (Culture, economy, environment, science \& technology, community, urban and rural regions, life condition). Secondly, the items were reviewed and discussed by a panel consisting of city management professors and officers from the bureau of Shanghai Expo. The panel suggested cancelling items about networks among stakeholders, and adding in low-carbon items. Finally, 42 items along seven dimensions were confirmed after revision and rewording.

\section{Data Collection}

Questionnaire survey was used in the study, consisting of demographic questions and questions relating to the perceived impacts of Shanghai Expo using the abovedeveloped scale. Between December 2010 and February 2011, eight trained university students were assigned to various public places (e.g., shopping malls, communities, public parks and university campuses) in Shanghai to collect data at different times of the day and different days of the week. Finally, 300 questionnaires were distributed to residents of Shanghai, who attended the event --including both Chinese nationals and expatriates living in Shanghai. 148 respondents from different age groups, genders, and cultural backgrounds were collected.

\section{Data Analysis}

The data then were analyzed with confirmatory factor analysis (CFA) and SEM using AMOS 6.0. CFA were used to examine the construct validity and adequacy of the measurement scale used in the study. Then, this paper chose three parameters to test the goodness-of-fit index of SEM: first is GFI, which should range between 0 and 1 , by convention GFI $>0.9$. Tucker-Lewis index (TLI) is the second indicators, also known as the Bentler-Bonett non-normative fit index (NNFI). If TLI is close to 1, it indicates the model is admissible. The third one is the approximate root mean square error (RMSEA). If RMSEA is less than 0.05, the model can be accepted (Wu et al., 2008).

\section{Results}

\section{Demographic Profile of Respondents}

The general profile of respondents can be seen in Table 1. The respondents were from 10 districts of Shanghai. They have a higher educational level, such as professors, PhDs, bachelor degree holders, foreign residents working in schools, and all of whom could be considered having enough knowledge to judge the event. Among the 148 respondents, there were 62 Shanghai local urban residents, 32 from foreign countries, 27 from the local rural areas, 14 living in Shanghai temporarily, and 13 guests from the neighboring cities. They respectively account for the total respondents of $41.89 \%, 21.63 \%, 18.24 \%, 9.46 \%$, and $8.78 \%$.

Table 1

Demographic Profile of the Residents

\begin{tabular}{lc}
\hline Socio-demographic variables & $\%$ \\
\hline Gender & \\
Male & 57.4 \\
Female & 42.6 \\
Total & 100 \\
Age & \\
$18-25$ & 30.2 \\
$26-35$ & 21.6 \\
$36-45$ & 27.1 \\
$46-55$ & 15.9 \\
56 and over & 5.2 \\
Total & 100 \\
\hline
\end{tabular}

Confirmatory Factor Analysis of Perceptions Scale

The constructed models' latent variables and measurement indicators are shown in Table 2. The measurement models were checked through CFA to test the reliability and validity. As shown in Table 3, Cronbach's $\alpha$ coefficient ranged from 0.689 to 0.866 , the latent variables composite reliability ranged from 0.694 to 0.871 . The average variance extraction value (AVE) of the seven dimensions exceeded 0.5 , indicating that the model have good inherent quality. All items loaded significantly under their respective factor, demonstrating the good convergent validity of the scale. Thus, this seven-factor model of perceptions was deemed appropriate for this study.

Table 2

Measurement Indicators in Latent Variables

\begin{tabular}{|c|c|c|c|}
\hline $\begin{array}{c}\text { Level I } \\
\text { Latent variables }\end{array}$ & $\begin{array}{c}\text { Level II Indicator } \\
\text { Measurable Variables }\end{array}$ & Level I Latent variables & $\begin{array}{c}\text { Level II Indicator } \\
\text { Measurable Variables }\end{array}$ \\
\hline \multirow{7}{*}{$\begin{array}{l}\text { F1 } \\
\text { Culture }\end{array}$} & X11 international perspective & \multirow{5}{*}{ F5 Community } & X51 public behaviors of residents \\
\hline & X12 multicultural life & & X52 improved relationship in \\
\hline & $\mathrm{X} 13$ tourism attraction & & neighborhood \\
\hline & X14 international mindset & & X53 social cohesion \\
\hline & X15 increased generosity & & X54 comfortable and safe lifestyle \\
\hline & X16 international behaviors & \multirow{2}{*}{$\begin{array}{l}\text { F6 } \\
\text { Rural regions }\end{array}$} & X61 relocation \\
\hline & X17 attractive architectures & & X62 improved educational \\
\hline
\end{tabular}


Kangjuan LV, Gyula Mosoni, Mengyi Wang, Xiaosong Zheng, Yan Sun. The Image of the 2010 World Expo: Residents'...

\begin{tabular}{|c|c|c|c|}
\hline \multirow{4}{*}{$\begin{array}{l}\mathrm{F} 2 \\
\text { Economy }\end{array}$} & X21 international status & \multirow{3}{*}{$\begin{array}{l}\text { F6 } \\
\text { Rural regions }\end{array}$} & environment \\
\hline & X22 investment & & X63 social welfare \\
\hline & X23 increased income & & X64 economic benefits \\
\hline & X24 job opportunities & \multirow{12}{*}{$\begin{array}{l}\text { F7 } \\
\text { Life Condition }\end{array}$} & X71 low carbon city \\
\hline \multirow{4}{*}{ F3 Science \& Technology } & X31 high-technology & & X72 safe buildings \\
\hline & X32 awareness of science & & X73 energy efficient \\
\hline & X33 friendly city & & X74 environmental protection awareness \\
\hline & X34 more humane dimension & & X75 energy-efficient architecture \\
\hline \multirow{8}{*}{ F4 Environment } & X41 improved environment & & X76 convenience of life \\
\hline & X42 air quality & & X77 sustainable consumption \\
\hline & X43 increased green space & & X78 social security system \\
\hline & X44 city beautification & & \multirow{2}{*}{$\begin{array}{l}\text { X79 improvement in medical } \\
\text { service and public hygiene }\end{array}$} \\
\hline & X45 public transit system & & \\
\hline & X46 convenient metro system & & X710 culture and entertainment \\
\hline & X47 clean subway & & X711 respectful life \\
\hline & X48 low carbon transport & & \\
\hline
\end{tabular}

Table 3

Test of Reliability and Validity

\begin{tabular}{cccc}
\hline Latent Variable & $\begin{array}{c}\text { Cronbach's } \\
\boldsymbol{\alpha}\end{array}$ & $\begin{array}{c}\text { Composite } \\
\text { reliability }\end{array}$ & AVE \\
\hline F1 & 0.768 & 0.773 & 0.541 \\
F2 & 0.866 & 0.871 & 0.608 \\
F3 & 0.819 & 0.805 & 0.510 \\
F4 & 0.797 & 0.806 & 0.592 \\
F5 & 0.725 & 0.722 & 0.523 \\
F6 & 0.689 & 0.694 & 0.501 \\
F7 & 0.734 & 0.757 & 0.544 \\
\hline
\end{tabular}

\section{Structural Equation Model Confirmation}

An SEM was constructed to further clarify and confirm the relationship among the variables. The constructed causal relationship diagram is noted as Model 1. However, the original Model 1 did not pass goodness-of-fit tests, which means the model adjustment is necessary. Model 1 was revised three times and then modified by reducing the latent indicators in level I, including F5 "community", F6 "rural regions" and F7 "life condition". Finally, RMSEA, TLI and GFI were $0.011,0.997$ and 0.998 respectively, which met the test requirements and suggested a good overall fit.

Fig. 1 shows how the indicators interact mutually and the strength of interaction. The numbers on lines in Figure 1 are path coefficients, which mean how much a variable can affect other variables. It presents that the path coefficients (factor loadings) of measurement indicators ranged from 0.66 to 1.54 . Most of the coefficients are above 0.80 , showing a strong relationship between variables. The path coefficients of firstorder latent variables (F1-F4) were 1.00, 1.00, 0.74 and 0.77 respectively.

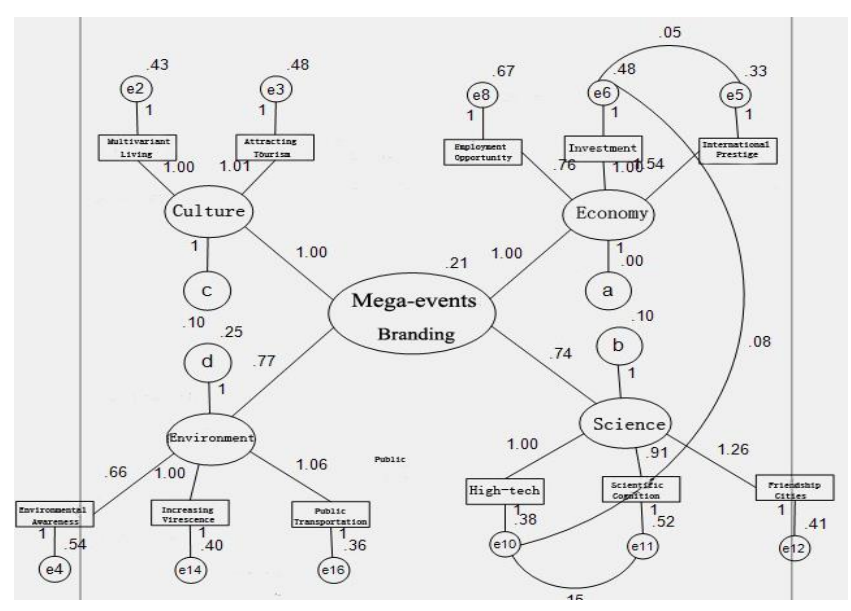

Figure 1. Revised Structural Equation model of Perceived Impacts of Shanghai Expo

Culture and economy coefficients are 1.00 , revealing they have a strong influence on the overall satisfaction of residents. Following is the environmental coefficient 0.77 and the science 0.74 , indicating they were not very significant comparatively.

Considering the relationship between latent variables and measurable variables, the results demonstrates that: firstly, cultural indicators named culturally-diverse life and booming tourism have similar effect on residents' cultural satisfaction with coefficient at 1.00 and 1.019. Secondly, among the three environmental indicators, the public transportation index is the highest. Thirdly, economic indicators "investment" brings the highest competitiveness to economic development, with the coefficient reaching 1.00. Fourthly, technology has three explicit indicators including high-technology, residents' understanding of science and technology, and their concept of a friendly city, with coefficients of 1.00, 0.91 and 1.26, respectively.

Overall, analyzing measurable variables with high scores in Figure 1, it shows that the World Expo has enriched culturally-diverse life, established more reliable and cleaner 
public transportation system, attracted more economic investment, developed high technology and increased people's knowledge of new technology innovations.

\section{Discussion}

The findings of this study revealed that Shanghai residents had more recognition of the effects of the Expo as multicultural life, environmental improvement, economic development and enhancement of technology. Culture and economy have a strong influence on the overall satisfaction of residents. As Wang et al. (2012) claimed, the main reason for visiting Shanghai is not only the city redevelopment and modernization, but also the combination of Western and oriental culture. However, residents did not perceived the expectations of Shanghai World Expo Bureau related to improve the quality of residents, enhance the neighborhood peace and community cohesion, and also promote communication between urban and outlying areas in Shanghai.

One of the objectives of this study is to verify any inconsistence between the government's well-publicized vision and residents' real perceptions after Shanghai World Expo. The concept of "harmonious cities" proposed by Bureau of Shanghai World Expo was based primarily on the harmony between man and nature, man and man, the spiritual and material content.

In this study, Shanghai Expo has facilitated the achievement of harmony between man and nature, which is consistent between government expectations and the perception of residents. Since 2002, Shanghai government has implemented a series of environmental protection policies (Meng \& Guo, 2010). It also helped expand the green space and improved the air quality. Since 2002, the average air quality rating is above $85 \%$ (Jin \& $\mathrm{Li}, 2010$ ). New environmental protection technology have been applied and generalized, such as new materials, ecologically sustainable and energy-saving building techniques. These efforts not only benefited the Expo visitors, but also created green assets for citizens.

Moreover, there is little mismatch about the spiritual and material content proposed by Bureau of Shanghai World Expo. On one hand, Shanghai attracted RMB 500 billion of investment during 2008 and 2009, as well as the large multinational and domestic companies (Jiang, 2011). Besides, tourism industry was promoted in Shanghai (Xu \& Wu, 2011). On the other hand, the Expo has created a platform for cultural exchanges while demonstrating profound Chinese culture like "China Pavilion". A variety of culture from different countries tends to converge, which contributes to improve cultural communication and understanding (Liang, 2010).

However, residents did not perceived the value related to the improvements of rural development, community and living conditions, which can be regarded as "harmony between man and man". Although new infrastructure construction and new "intelligent" technology have been changing the way of life of Shanghai residents, there still exist potential social problems. Hosting mega-events may cause inconvenience such as increasing overall cost of living, excessive noise, traffic congestion, parking difficulties, restricted movement and access to public facilities by residents because of closure or overcrowding. Besides, it has breakdown in original community structures, intensified polarization of city populations and social inequity (Chain, 2009; Shin \& Li, 2013).

The results analysis above indicates that the concept "harmony society" of 2010 Shanghai Expo is not totally recognized by local residents. It does not mean this event is not successful. Recent studies have proved that the Expo is a successful marketing strategy for Shanghai, and enhanced the city's international reputation on the global stage (Wu et al., 2007; Xue et al., 2012). But citizens' perceptions and consensus on government's advertising may be a key factor influencing the outcome of international mega-events (Wang et al., 2012). Potential negative attitudinal tendencies of Shanghai residents may undermine the official branding efforts and limit the ability of Shanghai to develop from a regional hub to a truly global city. Therefore, it is necessary to think about the consensus problem for Shanghai government, even though there were no protest or extreme behaviors.

In order to ensure a better congruence between image communication and the actual lived experience by residents, Shanghai authorities could take following suggestions: First, effective communication and information distribution between the government and residents is necessary to minimize value conflicts and to develop mutually acceptable goals. Second, involving residents in the planning and decision-making process through issue-based institutional mechanisms will enhance their understanding and collaboration in public policy, which can receive more support finally. In a word, more sustained efforts are vital to substantially improve the quality of residents' life.

\section{Conclusion}

This paper explored the image of the 2010 World Expo from resident's perspective, and verified whether the vision "harmonious cities" proposed by government has been consistent with local residents' actual perceptions through residents' attitudinal survey after the event and a SEM analysis. The results of this survey show that the "harmony society" identity proposed by Shanghai World Expo Bureau is not totally accepted by its dwellers. Local residents have a high recognition and satisfaction about positive changes produced by events in culture, environment, economy, science and technology, which represent the achievements in harmony between man and nature, as well as harmony between spiritual and material content. Nevertheless, they do not perceive the improvement of harmonious relationship among communities, interactions between urban and rural areas, as well as their living conditions according to this study, which refer to the harmony between man and man. This gives evidence that social representative theory plays an important role in mega-event.

This paper aims to reveal the inconsistence between governments propagandizing benefits from holding megaevents and citizens' real experience. It is notable that the mismatch is related to the existence of many social challenges and the absence of a two-way process of communication. From the residents' perception, social problems inner the city such as social equity, city polarization in the hosts are difficult to be improved just through one mega-event. In this sense, 
Shanghai should pay special attention to real perceived intergroup relations and residents' recognition in future city megaevents. Residents' participation in policy making process will improve their understanding and obtain their supportive attitude.

Despite the contribution to research, this study has limitations. First, there was no baseline data to perform a longitudinal study to see if residents' perceptions had changed over time. Secondly, this paper focuses on the local residents' perception and satisfaction without other stakeholders, which is not complete despite the representativeness. Thus, future studies should add in longitudinal comparison conducted among different time periods. It is also proposed that other stakeholders of mega-events such as entrepreneurs and foreign visitors should be included in the further research, in order to add depth to the impacts analysis of these events.

\section{References}

Agha, N., Fairley, S., \& Gibson, H. (2012). Considering legacy as a multi-dimensional construct: The legacy of the Olympic Games. Sport Management Review, 15(1), 125-139. https://doi.org/10.1016/j.smr.2011.08.004

Andereck, K. L., Valentine K. M., Knopf, R. C., \& Vogt C. A. (2005). Residents" Perceptions of Community Tourism Impacts. Annals of Tourism Research, 32 (4), 1056-1076. https://doi.org/10.1016/j.annals.2005.03.001

Andrea, C., Calvin, J., \& Max, M. (2009). Assessing the Environmental Impacts of Mega Sporting Events: Two options. Tourism Management, 30, 828-837. https://doi.org/10.1016/j.tourman.2008.12.006

Maiello, A., \& Pasquinelli, C. (2015). Destruction or construction? A (counter) branding analysis of sport mega-events in Rio de Janeiro. Cities, 48, 116-124. https://doi.org/10.1016/j.cities.2015.06.011

Ap, J. (1992). Residents' perceptions on tourism impacts. Annals of Tourism Research, 19(4), 665-690. https://doi.org/10.1016/0160-7383(92)90060-3

AP, J., \& Crompton, J. L. (1998). Developing and testing tourism impact scale. Journal of Travel Research, 37(2), 120-130. https://doi.org/10.1177/004728759803700203

Arne, F., \&Wolfgang, M. (2013). Mega-Events and Sectoral Employment: The Case of the 1996 Olympic Games. Contemporary Economic Policy, 31(3), 580-603. https://doi.org/10.1111/j.1465-7287.2012.00327.x

Baum, T., Deery, T., Hanlon, C., Lockstone, L., \& Smith, K. (2009). People and work in events and conventions: A research perspective. Oxfordshire, UK: CABI. https://doi.org/10.1079/9781845934767.0000

Brain, M. M., \& Mark, S. R. (2013). Hosting Mega-Events: A Guide to the Evaluation of Development Effects in Integrated Metropolitan Regions. Tourism Management, 34, 238-246. https://doi.org/10.1016/j.tourman.2012.03.011

Chain, Dion, (2009) Residents' perceptions of the 2010 FIFA World Cup : a case study of a suburb in Cape Town, South Africa. CPUT Theses \& Dissertations. Paper 123.

Chernushenko, D., \& Stubbs, D. (2005). Guidelines for greening sports events. www.committedtogreen.org.

Fredline, E. (2005). Host and guest relations and sport tourism. Sport in Society, 8, 263-279. https://doi.org/10.108 0/17430430500087328

Fredline, E., \& Faulkner, B. (2002). Variations in residents' reactions to major motorsport events: why residents perceive the impacts of events differently. Event Management, 7(2), 115-125. https://doi.org/10.3727/152599501108751524

Getz, D., (2008). Event tourism: Definition, evolution, and research progress in tourism management. Tourism Management, 29(3), 403-428. https://doi.org/10.1016/j.tourman.2007.07.017

Gursoy, D., Jurowski, C., \& Uysal, M. (2002). Residents attitudes: a structural modeling approach. Annals of Tourism Research, 29(1),79-105. https://doi.org/10.1016/S0160-7383(01)00028-7

Hooper, I. (2001). The value of sport in urban regeneration. In Sport and the City: the Role of Sport in Economic and Social Generation, Routledge, London.

Huang, H. C. (2012). Influence of international mega sport event towards cognition of economic, social-cultural and environmental impact for residents: A case study of the 2009 Kaohsiung World Games. Natural Resources and Sustainable Development II, 3392-3397. https://doi.org/10.4028/www.scientific.net/amr.524-527.3392

Hyun, J. K., Dogan G., \& Soo-Bum L. (2006). The Impact of the 2002 World Cup on South Korea: Comparisons of Pre- and Postgames. Tourism Management, 27, 86-96. https://doi.org/10.1016/j.tourman.2004.07.010

Jiang, Y. X. (2011). Brief Analysis on the Influence and Solutions of World Expo to Foreign Trade in China[J]. Modern Business (32), 181-182.

Jing, N., \& Rong, Li. (2010, November). City marketing from the perspective of Shanghai World Expo. Orient Academic Forum (pp. 86-98).

Jones, C. (2008). Assessing the Environmental Impact of a Major Sporting Event. Tourism Economics, 14, 343-360. https://doi.org/10.5367/000000008784460382

John, A. (2002). Festival and special event management. Beijing: China Machine Press, 6.

Kiki, K., Kostas, K., Heather, G., Brijesh, T., Matthew, W., Sue, G., \& Willie, C. (2013). Quality of Life, Event Impacts, and MegaEvent Support among South African Residents before and after the 2010 FIFA World Cup. Journal of Travel Research, 
52(5), 631-645. https://doi.org/10.1177/0047287513478501

Matheson, VA. (2009). Economic Multipliers and Mega-Event Analysis. International Journal of Sport Finance, 4(1), 63-70.

Kavaratzis, M., \& Ashworth, G. J. (2006). City branding: An effective assertion of identity or a transitory marketing trick? Place Branding and Public Diplomacy, 3(2), 183-194. https://doi.org/10.1057/palgrave.pb.5990056

Ke, Xue, Xi, Chen., \& Ming, Yang, Yu. (2012). Can the World Expo change a city's image through foreign media reports? Public Relations Review 38, 746-754. https://doi.org/10.1016/j.pubrev.2012.06.013

Kim, S., Ao, Y., Lee, H., \& Pan, S. (2012). A study of motivations and the image of Shanghai as perceived by foreign tourists at the Shanghai EXPO. Journal of Convention \& Event Tourism, 13(1), 48-73. https://doi.org/10.1080/15470 148.2012.651972

Liang, Z. C. (2010). China's Cultural Soft Power Construction study of the World Expo opportunity and enlightenment. Work \& Study Abroad (12), 83-84.

Li, Zhang., \& Zhao S. X., (2009). City branding and the Olympic effect: A case study of Beijing. Cities 26, $245-254$. https://doi.org/10.1016/j.cities.2009.05.002

Lucio L., Giuliano, N., Jurong, G., \& Zhu, S. C. (2011). Mega-events as drivers of community participation in developing countries: The case of Shanghai World Expo. Tourism Management, 32, 1474-1483. https://doi.org/10.10 16/j.tourman.2010.12.008

Luo, Q. J., \& Lu, X. Y. (2011). Economic Impact Assessment of Mega Sports Event from the Perspective of Visitors' ExpenditureTaking Guangzhou Asian Games as Example. China Sport Science, 31(9), 3-18.

Maximos, M., Eleni, T., \& Barrie H. (2004). Impacts of the Olympic Games as Mega-Events. Municipal Engineer, 157, $209-220$. https://doi.org/10.1680/muen.2004.157.3.209

Meng, X., \& Guo, Y. D. (2010). What Does Shanghai Economy Gain from 2010 Exposition?---An Events Industry Perspective. East China Economic Management (6), 20-24.

Moscovici, S. (1982). The coming era of social representations. In Codol, J. P., \& Leyens, J. P. (Eds.), Cognitive approaches to social behavior. The Hague: Nijhoff. https://doi.org/10.1007/978-94-009-7612-2_4

Owen, JG. (2005). Estimating the cost and benefit of hosting Olympic Games: what can Beijing expect from its 2008 Games? The Industrial Geographer 3(1), 1-18.

Pasotti, E. (2013). "Out of control: City branding and protest in Tel Aviv" RC-21 Conference in Berlin, August 29-31.

Poul Houman Andersen, Nicole Cook, \& Jane Marceau. (2004). Dynamic innovation strategies and stable networks in the construction industry Implanting solar energy projects in the Sydney Olympic Village. Journal of Business Research 57 , 351- 360. https://doi.org/10.1016/S0148-2963(02)00391-0

Preuss, H. (2007). The conceptualisation and measurement of mega sport event legacies. Journal of Sport \& Tourism, 12, 207228. https://doi.org/10.1080/14775080701736957

Qian, Y., Lu, L., \& Zhu, F. B. (2011). The Study on Visitors' Perceived Value on Shanghai World Expo Based on Fuzzy-IPA. East China Economic Management, 25(9), 8-12.

Ritchie, J. R. B., \& Aitken, C. E. (1984). Assessing the Impacts of the 1988 Olympic Winter Games: The Research Program and Initial Result[J]. Journal of Travel Research. 65-78

Shanghai Expo. (2008). Yu Zhengsheng stresses "better city, better life, and better friendship." Retrieved from 〈http://en.Expo2010.cn/a/20080614/000018.htm〉.

Shin, H. B., \& Li, B. (2013). Whose games? The costs of being 'Olympic citizens' in Beijing. Journal of Environment and Urbanization, 25, 1e18. https://doi.org/10.1177/0956247813501139

Smidt-Jensen, S. (2006). City branding: lessons from medium sized cities in the Baltic Sea Region. In Medium sized cities in dialogue around the Baltic Sea (ed.). Danish Centre for Forest, Landscape and Planning, KVL.

Tosun, C. (2002). Host perceptions of impacts: a comparative tourism study. Annals of Tourism Research, 29(1), $231-245$. https://doi.org/10.1016/S0160-7383(01)00039-1

Lorde, T., Greenidge, D., \& Devonish, D. (2011). Local residents' perceptions of the impacts of the ICC Cricket World Cup 2007 on Barbados: Comparisons of pre- and post-games. Tourism Management 32, 349-356. https://doi.org/10.101 6/j.tourman.2010.03.004

Wang, H., Xiaokaiti, M., Zhou, Y., Yang, Y., Liu, Y., \& Zhao, R. (2012). Mega events and city branding: A case study of Shanghai World Expo 2010. Journal of US-China Public Administration, 9(11), 1283-1293.

Wang, Zhe., Zhou, Li., \& Shi, Jing. (2011). On the beauty of green expo architecture and sustainable development-taking "China Pavilion" as an example. Procedia Engineering 21, 163-167. https://doi.org/10.1016/j.proeng.2011.11.2000

Wonyoung, Kim., Ho, Mun, Jun., Matthew, Walker., \& Dan, Dran. (2015). Evaluating the perceived social impacts of hosting large-scale sport tourism events: Scale development and validation. Tourism Management 48, 21-32. https://doi.org/10.1016/j.tourman.2014.10.015

World Expo Shanghai 2010 Official Website (2006, December 21). City leaders unveil harmony blueprint. Retrieved from http://www.expo2010.cn/expo/expo_english/oe/scf/sen/userobjectlai38941.html. 
Wu, F., Xu, J., \& Yeh, A. G. O. (2007). Urban Development in Post-Reform China: State, Market, and Space. Routledge, London

Wu Y. X., Ao Y. B., Ang, D. J., \& Zhu, H. Y. (2008) SEM-Based Research on Integration between Project Management and Supplier Management. 2008 International Conference on Management Science \& Engineering, 1654-1659. https://doi.org/10.1109/ICMSE.2008.4669127

Xiaoling Z. (2013). Going green: Initiatives and technologies in Shanghai World Expo. Renewable and Sustainable Energy Reviews 25, 78-88. https://doi.org/10.1016/j.rser.2013.04.011

Xu, X., \& Wu, Z. P. (2011), Analysis on the Influence of World Expo to Major Economic Indicators of Shanghai [J]. Science and Technology Management Research (21), 76-80.

Yang S. Y., \& Wu, J. J. (2012). The Diagnosis of Different Education Degree Influence upon the Perception to the World Expo among Shanghai Residents. Journal of Shanghai Institute of Technology, 12(3), 243-251.

Yu, L., Wang, C., \& Seo, J. (2012). Mega event and destination brand: 2010 Shanghai Expo. International Journal of Event and Festival Management, 3(1), 46-65. https://doi.org/10.1108/17582951211210933

Zhou, Y., \& John, Ap. (2009). Residents' Perceptions towards the Impacts of the Beijing 2008 Olympic Games. Journal of Travel Research, 48 (1), 78-91. https://doi.org/10.1177/0047287508328792

The article has been reviewed.

Received in December, 2012; accepted in April, 2017. 